\title{
SCIENTIFIC APPROACHES TO UNDERSTANDING TACTICAL AND CRIMINALISTIC COMPLEXES AND PROBLEMS OF THEIR PRACTICAL APPLICATION
}

\section{Shevchuk V.M.}

The paper examines theoretical foundations of tactical and criminalistic complexes and their practical application in the criminal proceedings. Scientific approaches to understanding notion «tactical and criminalistic complex», its functional purpose in the investigative and judicial activities are analyzed. The history of the origin, development and formation of the tactical and criminalistic complexes as scientific criminalistic category and complex tactical means of practical activity in criminal proceedings are considered. It is proved that the doctrinal approaches to the definition the notion under consideration should be based on the differentiated understanding of such organizational and tactical means as a tactical operation and tactical combination which are relatively new, specific activity categories reflecting individual variants of tactical and criminalistic complexes means and reveal the functional aspect in the process of their realization. Tactical operation and tactical combination are considered not as competing criminalistic categories but, on the contrary, as complementary. Tactical and criminalistic complexes in the investigation of crimes are considered as certain instruments of evidence collection and verification. Proper representation of the essence of the tactical operation and its relation to other means of criminalistic tactics, tactical criminalistic complexes serve for the further development of criminalistics theory, improvement of the judicial and investigative practice. In the current conditions of reforming criminal procedural law, criminal justice bodies, research and analysis of the problems of tactical and criminalistic complexes and their application in counteraction to criminality are relevant and determined by the needs of practice. Development of problems of tactical and criminalistic complexes practical application is undoubtedly necessary for the further improvement of scientific foundations of criminal proceedings process with the purpose of its optimization and efficiency increase.

Keywords: tactical and criminalistic complex, complex means of criminalistic tactics, criminalistic complex, tactical operations, tactical combinations, criminalistic theory of tactical operations.

УДК $343.9(075.8)$

B. Н. Терехович, адвокат Коллегии присяжных адвокатов Латвии, доктор права, доцент,

Э. В. Ниманде, доцент кафедры уголовно-правовых наук Латвийского университета, доктор права, доцент

\section{ОСОБЕННОСТИ ПОНЯТИЯ ОРУЖИЯ В КРИМИНАЛИСТИЧЕСКОМ ОРУЖИЕВЕДЕНИИ}

С позициии современных основ криминалистического оружсеведения $и$ практики расследования преступных деяний описаны особенности криминалистического понятия оружия. Раскрыта сущность процесса конкретизации и определения криминалистического понятия оружия.

Ключевые слова: уголовное правоприменение, расследование преступных деяний, криминалистическое оружиеведение, объект познания криминалистического оружиеведения.

(C) Терехович В. Н., Ниманде Э. В., 2016 
Любая научно-исследовательская деятельность предусматривает не только получение новых достоверных знаний, но и обобщение, обозначение, систематизацию и публикацию этих знаний. Это требование выработано исторически и практически осуществляется в виде проведения тематических научных семинаров, коллоквиумов, конференций, издания различных сборников научных публикаций, монографий, учебной и методической литературы. Только так результаты научно-исследовательской деятельности могут быть доступны и приняты научным сообществом. Только в таком виде результаты научно-исследовательской деятельности могут передаваться последующим поколениям исследователей и использоваться в академическом, профессиональном образовании и практической деятельности.

В сфере расследования преступных деяний востребованы научные знания из различных областей. Эти знания образуют основание доказательной базы по любому уголовному делу и в состязательном уголовном процессе их используют как сторона обвинения, так и сторона защиты. Поэтому крайне важно их единообразие, общепринятая положительная научная оценка достоверности и практической ценности этих знаний.

Охраняя законом наиболее важные сферы прав и интересов личности и общества, в национальных источниках уголовного права всегда предусматривается ограничение на изготовление, приобретение, ношение и применение оружия как потенциально опасного предмета при совершении преступных деяний. Понятие оружия и его отдельных разновидностей используется в нормах уголовного права либо как предмет состава преступного деяния, либо как квалифицирующий признак объективной стороны состава преступного деяния, либо как факультативный признак объективной стороны состава преступного деяния.

В уголовном правоприменении использование знаний об оружии и специфике его применения, возможности идентификации, диагностики и классификации оружия и следов его применения всегда относилось к сфере специального познания и реализовывалось в виде криминалистической экспертизы ${ }^{1}$. Достоверность результатов криминалистической экспертизы и возможность их оценки с необходимостью требует научной обоснованности методики конкретного вида криминалистической экспертизы. Эти требования особенно явно востребованы в криминалистической экспертизе оружия и следов его применения, поскольку данный вид судебной экспертизы традиционно является обязательным в процессе расследования преступных деяний, совершенных с использованием оружия.

Научную обоснованность методики криминалистической экспертизы оружия и следов его применения образуют две составляющие: методологическая, описывающая научную сторону процесса получения результатов в пределах конкретного вида экспертизы, и предметная, описывающая теоретическую обоснованность основных понятий предмета конкретного вида экспертизы. Например, основным понятием криминалистической эксперти-

1 Подробнее см.: Терехович В. Н. Криминалистика. Конспект курса лекций / В. Н. Терехович. - Рига, 2008. - С. 103-114; Он же. Основы криминалистического исследования холодного оружия. - Рига, 2010. - С. 103-217. 
зы холодного оружия является понятие оружия. Суть этого понятия раскрывается в пределах криминалистического оружиеведения.

На протяжении исторического развития криминалистики ученые-криминалисты пытались обобщить и систематизировать знания об отдельных видах оружия и следах их применения. Этой работе предшествовали два этапа: целенаправленное обобщение судебной и экспертной практики и создание теоретических основ отдельных видов оружия и следов их применения. Ее ключевым моментом было определение логического объема криминалистически значимых видов оружия и формулирование критериев криминалистической оценки этих видов оружия и следов их применения. Реальность этого процесса такова, что динамика развития такого процесса определяется не только историческими, социально-экономическими, научно-техническими условиями, в которых работают ученые-криминалисты разных стран, но и той системой национального уголовного права, в которой предусматривается использование полученных знаний.

Для того чтобы правильно определить специфику оружия как основного объекта познания криминалистического оружиеведения прежде всего необходимо оговорить криминалистическую ценность тех предметов материальной действительности, которые определяются как оружие и следы его применения. Оружие не появилось в культуре человеческой цивилизации как элемент уголовно-правовых конструкций и не в связи с расследованием преступных деяний. Оно по своей сущности, прежде всего, является предметом материальной культуры народов. Нет ни одного народа, в истории которого не было необходимости, удовлетворяя свои интересы, нападать или защищаться от врагов, добывать пищу охотой и т. п. В целях увеличения эффективности такой деятельности человек изготавливал или приспосабливал предметы, применение которых способствовало оптимальному достижению такой цели. Исторически эти предметы получили название оружие. По своей сущности оружие - это разновидность орудия труда, конструктивные особенности и способ применения которого определялись необходимостью защиты и нападения. Таким образом, оружие - это такое орудие, которое предназначено для защиты или нападения. В современных военнотехнических дисциплинах комплекс технических средств обороны и нападения называется вооружением. Такова данность понятия «оружие», природа которого неразрывно связана с материальной культурой человеческой цивилизации.

Наше представление о логическом объеме понятия «оружие» находится в прямой зависимости от множества реально существующих или исторически существовавших конкретных образцов оружия. Логический объем такого множества ограничивается видами энергии, применение которой заложено в конструктивные особенности того или иного вида оружия. Эта идея положена в основу деления понятия «оружие» в военно-технических дисциплинах. Таким образом, выбирая классифицирующий признак, т. е. основание классификации - вид энергии, которая используется для реализации боевых свойств конкретного вида оружия, в военно-технических дисциплинах выделяют следующие группы оружия: «холодное оружие» 
(вид энергии - мускульная сила человека), «огнестрельное оружие» (вид энергии - энергия горения пороховых веществ), «оружие взрывного действия» (вид энергии - кинетическая энергия взрыва), «атомное оружие» (вид энергии - энергия ядерной реакции), «химическое оружие» (вид энергии энергия деструктивных, необратимых для биологических систем химических реакций) и т. П.

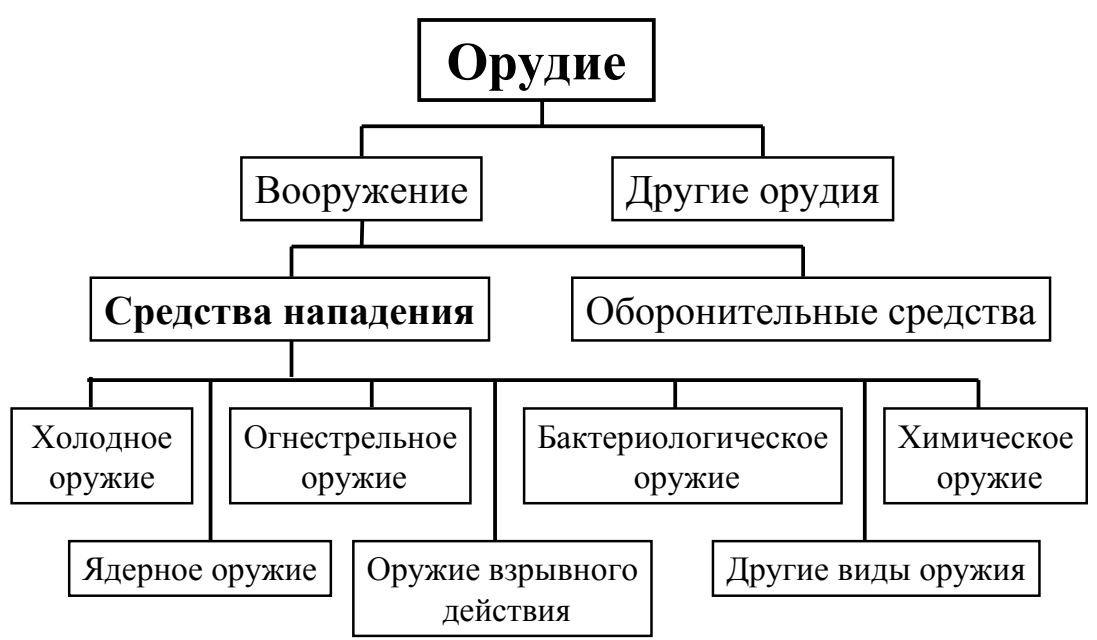

Рисунок. Классификация понятия «орудие»

Понятие «оружие» используют в различных областях знаний и деятельности человека. Однако каждая из этих областей использования понятия «оружие» вкладывает свой смысл, свое значение в это понятие. Например, для этнографа или историка материальной культуры народов, специалистов военно-технических дисциплин, специалистов в области торговли и т. д. понятие «оружие» наполняется разными смыслами. Не является исключением из этого правила и область расследования преступных деяний.

Понятие «оружие» как элемент уголовно-правовых конструкций - это предмет, конструктивные особенности и техническое состояние которого реально могут облегчить причинение им тяжких и смертельных телесных повреждений человеку. Предмет, которым невозможно причинить тяжкие и смертельные телесные повреждения человеку, в криминалистическом смысле оружием не является. Эти требования к оружию выработаны исторически криминалистической практикой расследования преступных деяний в пределах континентальной системы права. Поэтому определение оружия, используемое в военно-технических дисциплинах, не достаточно понятно дает представление о тех предметах, которые обобщены в криминалистическом понятии «оружие». Такое положение вещей не дает возможности в континентальной системе уголовного правоприменения напрямую ис- 
пользовать общепринятое энциклопедическое понятие «оружие». Этот недостаток устраняется конкретизацией понятия «оружие», вводя в данное понятие криминалистические ценности. Криминалистическая конкретизация понятия «оружие» позволяет выявить существенные признаки и четко определить логический объем криминалистического понятия «оружие», следовательно, определить понятно и точно понятие «оружие», пригодное для использования в криминалистической практике.

Правильное формирование криминалистического понятия оружия предусматривает ценностный характер понятий, вводимых в судебную теорию и практику. Истинный момент в юридическом мышлении вторичен по отношению к ценностному моменту. Поэтому при квалификации насильственных преступных деяний необходимо учитывать, насколько наличие орудия преступления, его предназначенность, техническое состояние облегчило либо могло бы облегчить совершение конкретного преступления. Следовательно, вводя понятие оружия в криминалистическую практику, необходимо учитывать реальную опасность применения конкретного предмета для причинения тяжких, либо смертельных телесных повреждений. Такую реальную опасность характеризуют предназначенность предмета и его пригодность для реализации предназначенных функиий. Таким образом, конкретизация объема криминалистического понятия оружия требует дополнительной классификации оружия с учетом его пригодности для реализации, заложенных в его конструкцию боевых свойств.

Как правило, на исследование экспертам поступают образцы оружия, технические параметры которых полностью соответствуют параметрам, изначально заложенным в процессе изготовления конкретного образца оружия. Однако экспертная и судебная практика показала, что насильственные действия с оружием, как правило, совершаются образцами оружия, бывшими в пользовании. Следовательно, имеющие в различной степени выраженные дефекты.

С криминалистической точки зрения важно, насколько имеющиеся у конкретного образца оружия дефекты влияют на пригодность реализации его боевых свойств. В случае, когда наличие дефектов у конкретного образца оружия незначительно снижает боевые свойства оружия, и такие дефекты легко устранимы в определенных условиях при наличии материалов и навыков, такой конкретный образец оружия необходимо признавать пригодным для применения. В случае, когда наличие дефектов конкретного образца оружия исключает возможность реализации изначально заложенных в него боевых свойств, такой образец оружия необходимо признавать непригодным для применения. Таким образом, оружие, в зависимости от технического состояния, подразделяется на две группы:

1) оружсие, пригодное для применения (технически исправное, имеющее дефекты);

2) оружие, не пригодное для применения.

Изложенное обстоятельство является основанием для утверждения того, что еще одним (помимо предназначенности) существенным признаком криминалистического понятия оружия будет реальная возможность реали- 
зации боевых свойств, изначально заложенных в конструкцию конкретного образца оружия, иными словами, техническое состояние оружия, для реализации его боевых свойств.

В теории уголовного права используется положение об индивидуальной уголовной ответственности, к тому же в судебной практике преступные деяния, в которых оружие выступает как предмет преступления (кража, изготовление, сбыт, ношение), либо как орудие преступления (применение оружия) встречаются случаи только с индивидуальным оружием. Это определяет целесообразность, при конкретизации криминалистического понятия оружия, провести также классификацию оружия в зависимости от числа людей, необходимых для применения оружсия. При выборе данного основания классификации, оружие можно подразделить на две группы:

1) индивидуальное оружие - оружие, которое переносит, подготавливает и применяет один человек. Например, кинжал, пистолет, граната и т. д.;

2) коллективное оружие - оружие, для перемещения, подготовки и применения которого необходимо двое и более человек. Например, онагр, аркбалиста, различные виды артиллерии и т. д.

Таким образом, существенным (с практической точки зрения) признаком криминалистического понятия оружия является также индивидуальность его применения. Однако с теоретической точки зрения можно предположить возможность появления в криминалистической практике случаев применения коллективного оружия. Например, в случаях расследования массовых беспорядков.

Конкретизация криминалистического понятия оружия по указанным основаниям наглядно иллюстрируется перекрестной классификацией оружия по двум основаниям:

1) по техническому состоянию - оружие пригодное для применения, оружие не пригодное для применения;

2) по числу людей, которое необходимо для владения оружием - индивидуальное оружие, коллективное оружие.

Именно эти основания (признаки) позволяют с учетом криминалистической практики конкретизировать криминалистическое понятие оружия. Таким образом, оружием в криминалистическом оружиеведении признается только индивидуальное оружие, техническое состояние которого позволяет реализовывать его боевые свойства.

\section{ОСОБЛИВОСТІ ПОНЯТТЯ ЗБРОЇ \\ В КРИМІНАЛІСТИЧНОМУ ЗБРОЄЗНАВСТВІ}

Терехович В. М., Німанде Е. В.

Із позииії сучасних основ криміналістичного зброєзнавства та практики розслідування злочинних діянь описано особливості криміналістичного поняття зброї. Розкрито сутність процесу конкретизаиії й визначення криміналістичного поняття зброї.

Ключові слова: кримінальне правозастосування, розслідування злочинних діянь, криміналістичне зброєзнавство, об 'єкт пізнання криміналістичного зброєзнавства. 


\title{
FEATURES OF THE NOTION OF WEAPONS IN THE CRIMINALISTICAL SCIENCE ON WEAPONS
}

\author{
Terehovich $V$. N., Nimande E. V.
}

The notion of the weapon and its individual variations are used in the norms of the criminal law or as the subject of a criminal act composition or as a qualifying attribute of a criminal act objective side, or as an optional feature of a criminal act composition objective side. By its essence, weapon is a kind of labor instruments whose structural features and method of use were defined by the need to protect and attack. The term "weapon» is used in various fields of knowledge and human activities. However, each of these areas of using notion "weapon» puts its importance into this notion. Definition of weapons used in military and technical disciplines does not clearly enough give an idea about the subjects which are summarized in the criminalistic notion of «weapons». The term «weapon» as an element of criminal law framework is the subject whose structural peculiarities and technical condition may actually facilitate causing serious and fatal injuries to man by them. The paper describes the criminalistic notion formation features on weapons from the position of the contemporary ideas of criminalistical science on weapons and practice of criminal acts investigation. It reveals the need and essence of concretizing signs of weapons criminalistic notion. As a basis for concretization of weapons notion is taken an encyclopedic notion, i. e., weapon is a tool designed for attack and defense. Concretization of this concept is carried out by cross-classification of weapons notion on two grounds - on the technical condition and the number of people which is necessary for working with a weapon. This cross-classification serves as a logical basis for the criminalistical definition of weapons. Thus, in criminalistic science on weapons a weapon is recognized only an individual weapon whose technical condition allows to realize its combating qualities.

Keywords: criminal law enforcement, investigation of criminal acts, criminalistical science on weapons, object of cognition of criminalistical science on weapons.

В. О. Малярова, професор кафедри криміналістики та судової експертології Харківського національного університету внутрішніх справ, доктор юридичних наук, доцент

\section{АКТУАЛЬНІ ПИТАННЯ АЛГОРИТМІЗАЦІї РОЗСЛІДУВАННЯ ОКРЕМИХ ВИДІВ ЗЛОЧИНІВ}

Розглянуто питання щзодо криміналістичного алгоритму розслідування як гнучкої системи науково розроблених і формалізованих приписів послідовного виконання в певному порядку оптимальних варіантів слідчих (розшукових) дій, негласних слідчих (розшукових) дій, оперативно-пошукових заходів та інших дій, об'єднаних задумом ефективного вирішення проміжних завдань розслідування злочину з урахуванням відповідних типових слідчих ситуацій. Надано авторське бачення алгоритму пошуку невідомого злочиния як послідовного вирішення конкретних завдань розслідування.

Ключові слова: пошукова діяльність слідого; установлення особи, яка вчинила злочин; алгоритм пошуку невідомого злочинияя.

(C) Малярова В. О., 2016 